\title{
Development of multi-channel marketing strategies for developing markets for low-cost consumer product goods
}

\author{
Fadye Saud Al Fayad \\ Department of Business Administration \\ Jubail University College \\ Kingdom of Saudi Arabia
}

\section{Key words}

Developing market; distribution channels; emerging markets; marketing; multi-channel; online.

\begin{abstract}
This study has examined the development of multi-channel marketing strategies and solutions that are intended for emerging or developing markets. The specific focus of the research has been on these multichannel marketing strategies in support of low-cost consumer product goods or CPGs meant for developing economies. Consequently, the research objectives of this research study were to determine the optimum approach to multi-channel marketing strategies for CPG firms entering developing markets. Additionally, the study also worked to analyze the effect of multi-channel marketing solutions and they might affect the composition of the supporting distribution channel for CPGs in developing markets. The illustrative market that has been relied upon for this study is Jordan. Jordan is a developing economy in the Middle East that has significant room for positive growth both economically as well as socio-culturally because of its location next to major areas of conflict. For Jordan, the expectation is that the multi-channel marketing strategy for a CPG retailer entering the market is going to focus on on-ground, traditional marketing channels with an emphasis on print and television while online marketing channels will be included but not yet fully developed.
\end{abstract}

Corresponding author: Fadye Saud Alfayad

Email addresses for the corresponding author:md@ucj.edu.sa

First submission received: $21^{\text {st }}$ December 2019

Revised submission received: $11^{\text {th }}$ February 2020

Accepted: $26^{\text {th }}$ March 2020

\section{Introduction}

This study examines the issue of the development of multi-channel marketing strategies designed for emerging and/or developing economies, hereafter referred to as developing economies, with a focus on low-cost consumer product goods (CPGs). Multi-channel marketing initiatives are an essential element in the contemporary marketplace regardless of the economics of the targeted market. However, for a developing economy, multi-channel solutions could very well be synonymous with success even in the short-term. Multi-channel marketing relates to the use of several different marketing channels that span both online and on-ground distribution pathways such as internet retailing solutions combined with bricks and mortars retail outlets but multi-channel also includes pathways such as the inclusion of cataloguing, texting, blogs, direct mailings, television, magazines or print and so on (Yu et al., 2018). Multi-channel marketing provides transaction opportunities for CPG marketers to move products across a range of different channels.

Of special relevance then to this study is the region being examined which is the Middle East. The Middle East consists of an enormous variety of both developing and developed markets. Furthermore, is a diverse retail marketplace characterized by countries that are stable politically, follow the rule of law and that have sound economic platforms. In contrast, the Middle East also has developing economies that are subject to extreme economic fluctuations, are unstable politically and that lack sound infrastructure. In general, the Middle East is a region that includes countries lying within the Asian continent with the exception of Egypt which is on the African continent and part of Turkey which is within the European continent (Goldschmidt, 2018). Additionally, the Middle East is just as often characterized as a region predominated by Islamic religious and cultural elements Hence, the Middle East is a region that is 
considered to rest between the Far East and Eastern Europe for the most part and the region is often subject to political, cultural and military discord.

One market within the Middle East that can be considered developing in character is Jordan. Jordan lies just to the east of Israel with an extensive border shared with Saudi Arabia to the east and a smaller border shared with Iraq to the northeast and a large border to the north shared with Syria. Of course, it is an established country having been formally established as a semiautonomous market following the end of World War I when it was governed by Britain but at the conclusion of World War II, Jordan won its independence from Britain and acquired its current form (Ryan, 2018). Despite its established borders and long historical presence in the region, Jordan as a market has remained in development economically for all of its modern existence. Therefore, Jordan offers an ideal market with which to explore how multichannel marketing for CPGs can, or cannot, be effectively leveraged with respect to developing markets.

\section{Literature Review \\ The Developing Market--Jordan}

Developing markets are primarily characterized as markets in which the consumers are described as low-income or having relatively little in the way of disposable incomes. While individually such emerging and developing markets may be characterized by consumers that are low income, collectively, the dense populations within these developing markets represent a rather significant market. Within the Middle East as a region, Jordan is one of the countries that can be considered to be a developing market. Thus, because of its status as a developing economy as well as its relative stability in a region otherwise troubled by socio-political upheavals, Jordan makes an ideal target for further study.

Jordan is not the largest country in the portion of the Middle East nor is it the largest in terms of population or economy. Additionally, Jordan has had ongoing political and geopolitical issues that have ensured that it has been unable to emerge from developing to developed status. The population of Jordan is roughly 10.5 million individuals with almost $70 \%$ of those being Jordanians, $13 \%$ being Syrian, almost $7 \%$ being Palestinian and another 7\% being Egyptian and of course $97 \%$ of the population is Islamic (Ryan, 2018 and Jordan, 2019). Islamic culture unites the population under the veneer of homogeneity but in fact it is quite a diverse culture considering large segments of the population are not from Jordan or do not trace their lineage directly to Jordan originally. The table below offers some glimpse into the economy of the country where it is evident that gross domestic product or GDP is fairly small and stagnant while GDP per capita remains low and unemployment rates remain high:

\begin{tabular}{|l|l|l|l|l|}
\hline $\begin{array}{l}\text { Jordan Economic } \\
\text { Data* }\end{array}$ & GDP & GDP Growth Rates & GDP Per Capita & $\begin{array}{l}\text { Unemployment } \\
\text { Rates }\end{array}$ \\
\hline 2017 & $\$ 89 \mathrm{~b}$ & $2.0 \%$ & $\$ 9200$ & $18.3 \%$ \\
\hline 2016 & $\$ 87 \mathrm{~b}$ & $2.0 \%$ & $\$ 9200$ & $15.3 \%$ \\
\hline 2015 & $\$ 85 \mathrm{~b}$ & $2.4 \%$ & $\$ 9300$ & $13.08 \%$ \\
\hline
\end{tabular}

*All monetary values are shown in US dollars **\% are estimates, averages or compilations of different sources (ibid)

\section{Table 1: Jordan Economic Data}

Considering the fact that GDP growth has remained in the $2 \%$ range in the recent past and GDP per capita has remained completely unchanged at $\$ 9200$ for years, it is apparent that Jordan is a developing market.

Its unemployment rate is likely understated with real unemployment rates, once on factors in issues such under-employment and part-time work without living wages and so forth, presenting significant problems for the government. Other characteristics of the country affirm its status as a developing market as well. For instance, the Jordanian economy is identified as being the smallest economy in the Middle East region while it simultaneously lacks sufficient supplies of fresh water, petroleum and a host of other natural resources that many other Middle Eastern countries have (Ryan, 2018). Furthermore, Jordan also faces other pressing issues that present a drain on its already insufficient state resources. The Civil War in Syria has led to the presence of more than 600 thousand refugees within its borders and it is $100 \%$ reliant on imported energy sources which account for an estimated 30\% of all imports into the country (Fabbe et 
al., 2019). Clearly, Jordan is a country that has largely been in a continue state of development since its inception in 1946.

\section{Multi-channel Marketing}

The development and application of multi-channel marketing initiatives is conceived of somewhat differently by different parties depending on their purpose or function. However, generally speaking, multi-channel marketing typically describes the links between CPG manufacturers or retailers and their targeted consumers. Specifically, multi-channel marketing involves the use of direct, indirect, and online, offline communication or distribution channels for products or services with the objective being a purchase decision being made by the targeted consumers (Banerjee and Bhardwaj, 2019). Where once it might have been sufficient to purchase ad space on a single large mass communication platform such as a magazine or television channel in order to achieve sales goals, this is hardly the case anymore. The result is the elevation in importance of multi-channel marketing.

In effect, the use and implementation of multi-channel marketing solutions is intended to unify a firm's marketing efforts across a range of different sales channels as it were. Without the presence of a unifying marketing plan a CPG manufacturer or retailer has to develop multiple marketing plans for the same products or product classes. This is summarized in the assertion that multi-channel marketing is the development of a unifying marketing strategy. A strategy that integrates several marketing channels, online and offline, that allows the firm to reach its targeted consumers with a single unifying message and to reach these targeted consumers when they want to make a purchase and where they want to make a purchase (Kimpel and Friedrich, 2015). Failure to understand this characterization of multi-channel marketing will leave a firm with little sense of the behavior of its targeted segments. Consequently, an appropriate planning technique to develop a multi-channel marketing strategy might include the following elements seen in the table below (Shahid and Ayaz, 2018):

\begin{tabular}{|l|l|l|l|l|l|l|l|}
\hline $\begin{array}{l}\text { Form of } \\
\text { Media }\end{array}$ & $\begin{array}{l}\text { R(each)E(engag } \\
\text { e)A(activate)N } \\
\text { (nurture }\end{array}$ & $\begin{array}{l}\text { Advert } \\
\text { ising } \\
\text { Cost }\end{array}$ & $\begin{array}{l}\text { Target } \\
\text { Market } \\
\text { Reach }\end{array}$ & Specialization & $\begin{array}{l}\text { Advertising } \\
\text { Complexity }\end{array}$ & $\begin{array}{l}\text { Credible/ } \\
\text { Not } \\
\text { Credible }\end{array}$ & $\begin{array}{l}\text { ROI vis-à- } \\
\text { vis ad } \\
\text { spend }\end{array}$ \\
\hline $\begin{array}{l}\text { Print } \\
\text { collateral }\end{array}$ & & & & & & & \\
\hline $\begin{array}{l}\text { Social } \\
\text { Media }\end{array}$ & & & & & & & \\
\hline $\begin{array}{l}\text { Search/A } \\
\text { d words }\end{array}$ & & & & & & & \\
\hline $\begin{array}{l}\text { Video } \\
\text { Streaming }\end{array}$ & & & & & & & \\
\hline $\begin{array}{l}\text { Press } \\
\text { Releases }\end{array}$ & & & & & & & \\
\hline
\end{tabular}

Table 2: Multi-channel Planning Table

As the information in this table aptly illustrates, each potential channel in a multi-channel marketing initiative must be accurately assessed in order to determine if its cost is justified through expected returns.

Basically, regardless of the specific channels that are integrated into a firm's multi-channel marketing strategy, there are specific benefits for utilizing a multi-channel marketing strategy. These benefits all increase the return on investment or ROI of the firm's marketing investment. And in developing markets such as Jordan, these cost-savings and cost-efficiencies can make an enormous difference on the success or failure of the firm's products within that developing market. The four primary advantages gained through the development and implementation of a multi-channel marketing strategy are (Manser, et al., 2017):

Expanded CPG awareness in the consumer through the integration of multiple potential touchpoints for the targeted consumers and consumer segments 
More consistent and unified CPG messaging in which the brand identity and brand reputation are retained across multiple marketing channels.

Supporting consumer channel preferences by offering purchase opportunities on the channels that the consumers are known to inhabit or frequent whether online or offline

Acquisition of expanded datapoints where these expanded channels increase the consumer touchpoints which provide vital data with each interaction by the consumer

Hence, it is apparent that multi-channel marketing is an approach that offers great latitude for the firm seeking to enter into a developing market. Of course, developing markets have certain inherent constraints, such as poor technology infrastructure, that may inhibit certain marketing channels but in general, multi-channel marketing solutions are quite promising in character.

Multi-channel marketing is one of the most important aspects of any competitive CPG retailer's activities when entering a new market whether developed or developing. Multi-channel marketing strategy may not be the sole factor that decides whether a product or service will be completely accepted by the target market. However, multi-channel marketing strategies do directly influence how customers tend to perceive their respective needs and wants with regard to the product or service being marketed. In this fashion, multi-channel marketing strategy works to define for the customer the market entry messages formulated by the CPG retailer. These messages are then relayed to the customers' own network of contacts and acquaintances. Thus, when provided with this market entry message, customers act on the multi-channel marketing market entry message given them by making a purchase decision or, alternatively, offering some sort of market referral (McIntyre et al., 2016). Many CPG retailers and multichannel marketing managers insist that multi-channel marketing relies on the wants and desires of the customer.

These consumer needs that form the nucleus of the market entry message are the messages that focus on the target market whether on-ground or online. And yet, the insistence that this is the overall rule tends to ensure that a CPG retailer misses significant marketing opportunities in either on-ground channels or online channels depending on the composition of their multi-channel operations. The effort is, or should be, to create the CPG retailer's own market opportunities and this is especially true for developing markets. The opportunities then, among others, are those such as development of an entirely new CPG in order to respond to an identified need in the market. Furthermore, it is often the case that the market, especially the developing market, has no idea what it even needs vis-à-vis a new product or service targeting consumers in its borders.

A perfect illustration of this multi-channel principle of telling the customer what the customer actually wants can be found in Apple. Marketing messaging at the time of market entry based on the creation of a multi-channel marketing strategy at market entry reflects this sentiment of identifying a need in the consumer that the consumer did not even recognize. For instance, Apple is recognized as one of the world's most innovative electronics CPG retailers. This is because it has managed to develop and then introduce a retinue of unique products that many international markets were not even aware, they wanted or needed. This marketing case is clear in the iPod, the iPhone (all iterations) and of course the iPad. Evidence of this marketing strategy and unique capacity of multi-channel marketing to direct customer tastes can be found in a comment by Apple's former and late CEO Steve Jobs who commented that customers do not really know what they want but they recognize it when they see it (Tian and Da, 2016). Hence, as Apple first introduced the iPod, for instance there existed numerous MP3 digital music players.

The fact is that the market was not necessarily demanding a new MP3 player. Rather the consensus was that the market for MP3 players was a niche market and that the MP3 market was already overcrowded. Yet, by convincing the customer that digital music played on portable handheld devices were not just a luxury but rather a necessity like the Walkman had been, Apple's marketers managed to create consumer demand where none had previously existed. The market entry message that Apple's marketers created and then used to enter virtually every global market worked to convince customers that they did not just want an iPod but that they actually needed one in order to organize their musical files, desires and tastes (Zhang, 2019). This market entry message resonated with global markets whether 
developed or developing. The outcome has been what virtually all researchers determine to be a complete marketing success and a highly effective multi-channel marketing strategy for Apple.

Part and parcel of an effective multi-channel marketing strategy targeting developing markets such as Jordan is understanding what the objectives are for the strategy with respect to the distribution of the CPGs in the channel. This aspect of multi-channel marketing strategy is partially dependent upon the specific characteristics of the products as well as the characteristics of the particular marketplace being distributed in. The fact is that specific CPG characteristics have to be an integral part of the market entry considerations while developing a multi-channel marketing strategy. The implication is such that the multi-channel strategy has distribution objectives that align with the overarching marketing strategy of the producer, distributor, or retailer responsible for the multi-channel effort. Hence, for developing markets, distributors entering the developing market work to minimize costs while maximizing throughput activities across the channels selected (Dadzie et al., 2017):

CPG unit values: in general, if a CPG per-unit value is low, the supporting distribution channel will tend to be longer in character which results in smaller operating margins for the distributor with the observation being that high-value per-unit CPGs typically are supported through a firm salesforce rather than through supply chain intermediary firms

CPG standardization: the more standardized a CPG is in both form and function, are much more suitable to multi-channel distribution because less adaptation from one channel to the next is required whole less standardized CPGs typically require more representative resources across every channel

Size/weight: the fact is that large, bulky and/or heavy CPGs incur much higher per-unit shipping and handling costs as a ratio of their overall per-unit cost with the multi-channel effect being that such CPGs benefit from shorter supply chains within the multi-channel strategy

Complex CGPs: CPGs with higher degrees of product complexity benefit from or require a more direct-to-consumer distribution channel because they almost mandate a salesforce to support their distribution to consumers in the targeted marketplace and therefore complexity is a factor in selecting which channels to integrate into a multi-channel marketing strategy for developing markets

CPG lifecycle: the specific position of a CPG on the product lifecycle also affects the character of the multi-channel marketing strategy because CPGs that are relatively early in their lifecycle require greater representation and support in the target market

These factors must all be considered when identifying which specific marketing channels to include in a multi-channel distribution strategy. The distributing firm has to balance the necessities of each channel with the available resources of the firm regardless of how desirable a particular channel is. For instance, those individual channels that merit greater support such as a direct salesforce must be viewed in relation to the human capital and finance constraints of the CPG distributor entering the market. Failure to make such considerations a central element in the planning process for entering a developing market can leave the CPG distributor lacking sufficient resources post-entry.

Finally, the multi-channel marketing strategy for a developing market and, for that matter, any sort of market, must also have an effective way to revise the multi-channel strategy post-entry. There are certain assumptions that must be accepted which influence how, when and in what way individual channels are adjusted in the post-entry environment as a CPG distributor's marketers receive feedback from the multi-channel marketing solution. This includes assumptions such as the recognition that direct forms of CPG distribution are more readily adjustable and adaptable because the CPG distributor retains a higher level of control over the operators within the respective channels selected (Bang et al. 2016). In contrast, if all the channels in the multi-channel effort depend upon $3^{\text {rd }}$ party operators up and down the supply chain supporting each channel, then introducing, and making adjustments quickly is problematic. Furthermore, there are market related factors that also affect the character of how the multi-channel marketing strategy is managed. If there are seasonality or seasonal buying considerations for the CPGs in question, then intermediaries within each supporting supply chain in the target market that have more flexible CPG storage facilities/solutions are much more desirable because storage capacity works to flatten variations in the supply chain due to over-production, under-production, shifts in demand and CPG returns for example (Rauch et al., 2016). All of these multi-channels and supporting supply chain considerations must be integrated into the framework for the CPG multi-channel strategy. 


\section{Research methodology}

The marketing framework within which a multi-channel marketing strategy is created involves segmentation activities as a matter of course. Furthermore, any marketing strategy developed for market entry incorporates some elements of segmentation, target market development and so forth just to determine which channels reach each particular audience. One of the most important aspects then within any marketing segmentation strategy is the move to narrow down the individual consumer markets into distinct groups of CPG customers. This process of target market identification can be achieved in different ways to be sure. However, it is the final outcome that must result in a set of different market segments that are simultaneously measurable, uniquely identifiable, and strategically distinct from one another while still unifying around a common CPG theme (Bang et al., 2016). Should this marketing process around segmentation be undertaken haphazardly or inaccurately, then at the very least, the resulting multi-channel marketing strategy will not be cost effective. Therefore, multi-channel marketing strategies must be fundamentally derived from proper segmentation formulas.

In order fully explore the subject of the multi-channel in developing markets vis-à-vis CPGs, this study incorporates a series of three core hypotheses. These hypotheses are formulated in order to either confirm the efficacy of a multi-channel solution or to affirm the ineffectiveness of a multi-channel solution. The three hypotheses that guide this study through the research process are detailed below:

H1 :Off-line marketing channels are the most effective in developing markets

$\mathrm{H} 2$ :On-line marketing channels are the most effective in developing markets

$\mathrm{H} 3$ :A multi-channel incorporating both off-line and on-line marketing channels is the ideal solution for developing markets

The affirmation or disaffirmation of these hypotheses provides the chief value in this study. The supposition being that depending on which hypotheses are affirmed or disaffirmed, a CPG marketer can thereby formulate the most effective marketing solution for a given developing market.

The research model developed for this study is based on a threefold process in which each of the three elements contribute to the substantiation of the other two. This is a triangulation design that is meant to result in more reliable findings based on a higher level of validity with respect to the data. The research model is displayed in the figure below:

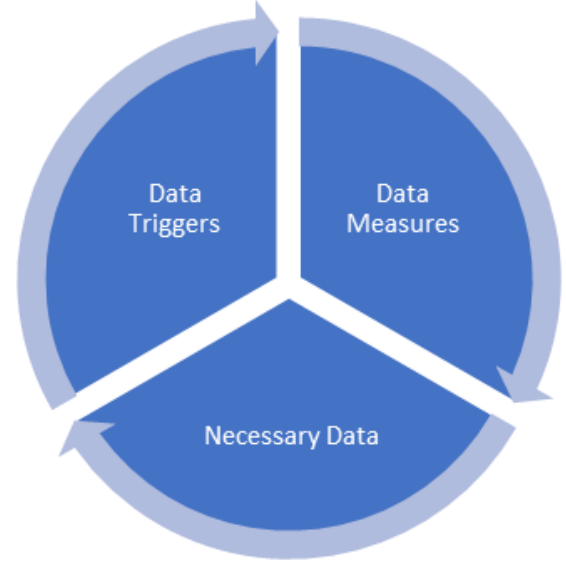

Figure 1: Research Design Model

This research design is a triangulated approach to data collection, data analysis and data validity. The emphasis in this design is the characterization of the data in each of the three pillars: 1) data triggers involve elements such as consumer behavior such as buying decisions, 2) data measures indicating how transactions are recorded and presented, and 3) ensuring that the data actually reflects the phenomenon that it is supposed to reflect (Hulland et al. 2018). Triangulation is an effective way to elevate a study's overall reliability and validity.

This research project has analyzed the primary data through descriptive statistics. This is an analytical process that represents the mean, the standard deviation, modality. The analysis also includes inferential statistics analysis utilizing factor analysis and path analysis in order to make predictive 
statements regarding the data. The study's hypothesis testing resulted in a confidence level of $95 \%$. This confidence level was arrived at through a Z-test that made use of SPSS. SPSS was used to analyze factors such as the Structure Equation Model or SEM. This process ensured that the research study model was able to effectively deal with the empirical data within the study. This analytical approach was based on the following assumptions where P-Values $>0.05$, GFI > 0.8, AGFI $>0.8, \mathrm{CFI}>0.8$, RMR $<0.1$ and the Chi Square $<2$. This approach was based on the understanding that the multi-channel marketing strategies offer unique utilities for developing markets that can be leveraged in those markets based on the following points:

1. On-ground traditional retail channels ensure that firms entering developing markets focus on factors of convenience for consumers such as access $/$ mean $=4.6$, service times $=4.5$ and transportation $=4.8$

2. On-ground/on-line linkages should exist with the firms expecting on-line informational support $=4.4$, adequate informational resources for $\mathrm{CPGs}=4.3$ and service speed for consumers $=4.2$

3. Online marketing channels for firms entering the developing market must have relatively fast data transfer times $=4.6$, data accuracy $=4.6$, and rapid service time support $=4.5$

The data indicates that there is not, in the developing market context, a significant amount of difference in these factors between on ground and online channels with significance levels at 0.05 . And yet, having online support does speed up the on-ground service times. Consequently, there is a significance level that differs markedly when firms entering developing markets have greater resources to leverage with significance measuring at levels above 0.07 and similar.

\section{Findings/results}

The development of a multi-channel marketing market entry message that actually informs customers about themselves and their needs is vital. It is a critical aspect of multi-channel marketing messaging for either developing or developed markets. Additionally, a market entry message in the multi-channel context targeting developing markets, is often more effective in on-ground channels due to the control that the CPG firm's marketers retain over the messaging process (Ailawadi and Farris, 2017). Additionally, it is also or can be indicative of how CPG retailers can design and mold their research and development activities around new concepts. These concepts being based not necessarily on specific market-driven research but rather on identifying what it is that the target market customers are actually not discussing. This approach is generally reflected in the marketing literature. For instance, some market analysts hypothesize that some consumer products or services can be developed not on customer tastes or preferences per se but rather on certain identified values and socio-cultural value systems which customers may not even be conscious (Bahadir et al., 2015). The point being made is that few if any customers tend to consciously think of their own particular value systems and what factors may influence them. Therefore, consumers may not even be able to anticipate their own sociocultural desires in the first place. The result being that a CPG firm initiating a market entry strategy in a developing market may utilize multi-channel marketing to create a need where none exists. Attempting to merely buy one's way into a developing market by performing market-based research specific to a given developing market does not necessarily identify a need.

Among the more important observations that can be made relative to this perspective that multichannel marketing drives customer tastes, preferences and desires is trend related. The idea is that multichannel marketing that is focused on established customer trends in a given market is still necessary as well but that current trends do not necessarily translate into real opportunities. Thus, CPG retailers and their respective multi-channel marketing strategies should not immediately latch onto completely onground marketing solutions or completely online marketing initiatives. Rather, marketing activity directed at the established customer preferences in the targeted market should form a baseline of marketing activity from which multi-channel solutions are then developed. This outcome arises because established CPGs must constantly be revised and have their messaging reinforced. Such revision and reinforced messaging works to maintain or achieve sales targets. These sales targets occur throughout the product life cycle. This can be maintained through multi-channel marketing efforts that target word-ofmouth advertising or, alternatively, social media referrals (Manser et al., 2017). Additionally, CPG retailers learn to create market opportunities through guiding customer tastes and preferences. These in 
turn also work to maintain sales through identifying customer desires. Multi-channel marketing is not a strategy that can be designed based on a predetermined formula. In contrast, multi-channel marketing targeting developing markets especially is more art that science meaning that marketers have to approach each one independently.

The study's analytical model looked into the correlation relating to the study's independent variables. The intention has been to ensure that factors such as multi-collinearity did not adversely affect the statistical analysis of the data. The research analysis relied on the following approaches in which several observations regarding distribution can be made. These include the observation that univariate distributions among the data integrated kurtosis as well as skewness with an average spread of +/- 3.0 while the Kolmogorov analysis integrated interval and ratio testing where statistical values including mean shown as X, standard deviation shown as SD, skewness shown as SK, and kurtosis shown as KU. This analysis is displayed in the table that follows:

\begin{tabular}{|c|c|c|c|c|c|c|}
\hline \multirow[t]{2}{*}{ Marketing Channels } & \multicolumn{2}{|c|}{$\begin{array}{l}\text { Developing } \\
\text { Markets }\end{array}$} & \multicolumn{2}{|l|}{$\begin{array}{l}\text { Developed } \\
\text { Markets }\end{array}$} & \multirow[t]{2}{*}{ KU/SK } & \multirow[t]{2}{*}{ t-test } \\
\hline & $\overline{\mathrm{X}}$ & S.D. & $\bar{X}$ & S.D. & & \\
\hline \multicolumn{7}{|c|}{ On-ground Marketing Channels } \\
\hline 1. OnG1 & 4.52 & .604 & 4.56 & .727 & $-1.235 /-184$ & -.598 \\
\hline 2. OnG2 & 4.62 & .661 & 4.42 & 0.725 & $-1.202 /-480$ & $2.682 *$ \\
\hline 3. OnG3 & 4.20 & 1.000 & 4.56 & .727 & $-1.857 / 2.851$ & $-3.583 *$ \\
\hline 4. OnG4 & 4.32 & .780 & 4.72 & .695 & $-1.102 /-.680$ & $-5.096 *$ \\
\hline 5. OnG5 & 4.80 & .493 & 4.44 & .727 & $-1.493 / 1.191$ & $5.810 *$ \\
\hline \multicolumn{7}{|c|}{ On-ground and online Marketing } \\
\hline \multicolumn{7}{|l|}{ Channels } \\
\hline 1. ONL/ONG1 & 4.22 & .604 & 4.58 & .725 & $-.484 /-1.297$ & $-7.346 *$ \\
\hline 2. ONL/ONG2 & 4.02 & 1.000 & 4.59 & .735 & $-.939 /-.306$ & $-6.549 *$ \\
\hline 3. ONL/ONG3 & 4.02 & .780 & 4.48 & .650 & $-.887 /-.746$ & $-6.551 *$ \\
\hline 4. ONL/ONG4 & 4.32 & .493 & 4.59 & .720 & $-.933 / . .131$ & $-5.268 *$ \\
\hline 5. ONL/ONG5 & 4.42 & .493 & 4.72 & .697 & $-.884 /-.221$ & $-4.970 *$ \\
\hline \multicolumn{7}{|c|}{ Online Marketing Channels } \\
\hline 1. ONL1 & 4.62 & .489 & 4.73 & .705 & $-1.492 / 1.192$ & -1.904 \\
\hline 2. ONL2 & 4.60 & .660 & 4.72 & .695 & $-1.689 / 1.298$ & -1.706 \\
\hline 3. ONL3 & 4.52 & 669 & 4.56 & .727 & $-1.143 / .038$ & -0.727 \\
\hline 4. ONL4 & 4.51 & .675 & 4.56 & .727 & $-1.003 / .040$ & -0.783 \\
\hline 5. ONL5 & 4.51 & .680 & 4.55 & .730 & $-1.001 / . .043$ & -0.772 \\
\hline
\end{tabular}

Table 3: Statistical Values of All Variables

The data in the table results in $1.85<\mathrm{SK}, 2.85$ for SU and a standard spectrum SEM for the text of concordance. Likewise, the differential examination of the data indicated that firms in developing markets produced $n=235$ while those in comparable developed markets resulted in $n=165$, respectively. The result is such that firms in developing markets tend to rely more on on-ground marketing channels with statistical significance being shown at $\mathrm{p}<0.05$ across most of the data points. The assumption being that on-ground channels in developing markets generally produce faster service times.

In turn, the most appropriate consumer segmentation of a broader group of CPG customers will then lead to actual targeted marketing material. The marketing collateral designed for developing markets is ultimately developed for each individual market segment that is identified in the consumer segmentation effort of a CPG firm. Consequently, consumer targeting for a CPG retailer entering a developing market depends upon the marketing collateral developed for each consumer segment that is identified. Hence, the consumer segmentation solution in which each of the target markets identified reflects CPG customer desires who share have in common or share certain traits that the CPG firm determines are a reflection of the firm's product qualities (Pansari and Kumar, 2017). This developing market targeting process for specific consumer segments is much more involved just differentiating a group of CPG customers. Instead, each consumer group and related sub-group of CPG targeted 
consumers must be measured or quantified in some way. This quantification should include factors like size as well as the market's growth potential, evaluated and reevaluated for potential shared values and if there are any existing competitor CPGs followed by pairing the CPG firm's core market objectives, its specific mission and long-term vision (ibid). The conclusion is such that the marketing firm should, so that it can develop and execute on more meaningful consumer targeting solution, have a good understanding of its own resources, the current position of the product's lifecycle and, finally, the level of variability in the developing country's marketplace. Thereafter, the CPG firm and its marketers can, once these factors are accomplished, begin to market in the country based on a more informed multi-channel marketing mix.

The outcome of the relativity tests indicate that the study's variables are reliable and valid with respect to the analytical paradigm being applied in the study. This relativity test is undertaken through the use of a structural equation model or SEM test (Jackson, 2015). The SEM results are displayed in the table that follows. Included is the fitness of the study's paradigm which is deemed to be appropriate to the topic being examined:

\begin{tabular}{|c|c|c|c|c|c|}
\hline $\begin{array}{l}\text { Appropriatenes } \\
\mathrm{s} \text { of Framework }\end{array}$ & Targe & d Levels & & Developing Markets & Developed Markets \\
\hline $\begin{array}{l}\chi^{2} / \text { degree of } \\
\text { movement }\end{array}$ & $0-3$ & Target & $<3$ & 2.207 & 2.807 \\
\hline Root Mean & $2-0$ & Target & $<0.05$ & 0.045 & 0.025 \\
\hline $\begin{array}{l}\text { Root Mean } \\
\text { Square Error } \\
\text { Estimate }\end{array}$ & $02-$ & Target & $<0.05$ & 0.025 & 0.020 \\
\hline Goodness of Fit & $2-0$ & Target & $>0.9$ & 0.890 & 0.924 \\
\hline $\begin{array}{l}\text { Adjusted } \\
\text { Goodness of Fit }\end{array}$ & $02-$ & Target & $>0.9$ & 0.900 & 0.908 \\
\hline
\end{tabular}

The data results indicate that the study's datapoints are reliable and valid in nature. The differences between developing markets and developed markets with respect to multi-channel marketing strategies upon market entry are significant. This indicates that greater consideration must be given to on-ground marketing solutions for developing markets versus developed markets.

Another aspect of the analysis, the descriptive and inferential statistics involves the utility of the hypothesis. In order to determine if the hypothesis actually questions the specific element that it should question vis-à-vis multi-channel marketing in developing markets, a hypothesis testing must take place. This hypothesis testing and its results is displayed in the table below:

\begin{tabular}{|c|c|c|c|c|c|c|}
\hline Study Hy & othesis & $\beta$ & St. Dev. & S.E. & $\mathrm{P}$ & SMC/R-Square \\
\hline \multicolumn{7}{|c|}{ Developing Markets } \\
\hline OFF & $\longrightarrow$ Inflection & 0.573 & 0.380 & 0.043 & $0.000 * * *$ & 0.757 \\
\hline OFFON & $\longrightarrow$ Inflection & 0.392 & 0.236 & 0.052 & $0.006 * *$ & 0.626 \\
\hline & $\longrightarrow$ Inflection & 0.532 & 0.345 & 0.045 & $0.000 * * *$ & 0.728 \\
\hline Hypothes & & $\beta$ & St. Dev. & S.E. & $\mathrm{P}$ & SMC/R-Square \\
\hline \multicolumn{7}{|c|}{ Developed Markets } \\
\hline OFF & $\longrightarrow$ Inflection & 0.825 & 0.420 & 0.042 & $0.000 * * *$ & 0.903 \\
\hline OFFON & $\longrightarrow$ Inflection & 0.498 & 0.335 & 0.034 & $0.000 * * *$ & 0.705 \\
\hline ON & $\longrightarrow$ Inflection & 0.226 & 0.224 & 0.022 & $0.026^{*}$ & 0.475 \\
\hline
\end{tabular}

$(\mathrm{p}<0.002), * *(\mathrm{p}<0.02), *(\mathrm{p}<0.05)$

Table 5: Data Outcome of the Hypothesis Test

The data outcome from the table above indicates that developing markets benefit more from onground multi-channel marketing solutions. The identified coefficient makes this clear with its 0.757 outcome. Conversely, the web-based multi-channel marketing solutions are inflected at 0.728 and 0.626 
each revealing that developed markets just benefit more from more sophisticated infrastructure and more sophisticated consumer behaviors.

Likewise, developed markets do benefit from on-ground multi-channel solutions as well. It is important that operational factors such as how consumers will actually pay for a purchase of a given product in a developing market is actually an important consideration. For instance, with respect to credit related transactions, the coefficient of 0.903 demonstrates an inflection point favorable to positive credit reliant transactions. The fact is that if a developing market lacks the sophisticated technology infrastructure to support with any degree of reliability, a digital purchase framework, then the inclusion of online related multi-channel solutions must be tempered with a healthy dose of reality.

The critical area that should inform a CPG company's market entry marketing strategy is the area of market segmentation and consumer targeting. This marketing area is critical for the CPG firm because it will depend on targeting developing markets and sub-markets in order to penetrate those marketplaces efficiently and effectively. Market segmentation involves a multi-channel effort that focuses on a large, broadly arranged group of potential CPG customers and then divides them into more condensed groups, develops more easily targeted consumer segments and identifies specific consumer traits (Maina, 2015). Therefore, it becomes incumbent on a CPG retailer interested in developing markets to understand that segmentation of the broader target market is vital. The fact remains that for any CPG retailer, the recognition should be made that each consumer is going to want or desire the same general types of products. Hence, through the process of consumer segmentation, a CPG retailer can isolate specific subgroups of CPG customers in any given developing market. This is how the decision to include specific onground or online marketing channels are made in that each identified consumer segment is going to be reached more optimally by specific marketing channels.

\section{Discussion and conclusions}

The research project demonstrated that the P-values in the analysis are at 0.06 in which the implication is such that the data in the SEM framework. The result is such that project's methodology aligns with the study's conceptual design. Developing markets and developed markets provide the relative sample groups of the research project.The findings indicated that all the best fit indexes from the SEM analysis. This was applied to both developing markets and developed markets. The findings manifested study criteria expressing a 0.65 factor load based on a target value of 0.40 loading expression. In the case of developed markets, all the best-fit indices from the SEM analytical framework integrate the study's criteria that express a 0.40 or higher loading factor. Both developing markets and developed markets had on-ground marketing channels that influence the adoption of both on-ground and online marketing channels supported by a coefficient greater than $50 \%$ within the analysis. Additionally, the research project confirms the fact that developed markets used and rely on online channels somewhat less than $50 \%$ found in the coefficient of $47.4 \%$. Therefore, considering that Jordan's economy has a gross domestic product or GDP of just $\$ 89$ billion and fairly low sustained growth rate of $2 \%$ year on year along with a per capita income of about $\$ 9,200$, there is little room in a marketing mix for heavy emphasis on online marketing channels. The population is simply not in a position to be fully segmented along economic lines in the online forum. Certainly, certain segments can be adequately targeted online, but these would be the exception rather than the rule.

In this way, from a multi-channel marketing perspective, consumer segmentation is fundamental to the development of an effective market entry plan. The multi-channel marketing mix is a series of differently arranged marketing channels that a CPG firm will use to target its segmented CPG customers. Thus, in order to segment a developing marketplace effectively, the CPG firm must be able to identify specific kinds of characteristics and consumer traits of each group of CPG customers. CPG consumer characteristics and traits should be measurable within each consumer segment and this allows a segmented multi-channel marketing solution to accompany the market entry plan (Andaleeb, 2016). If all of these various factors have been met, then the CPG firm and its marketing team can be reasonably confident that its multi-channel marketing strategies will be effective. 
Effective implies that the multi-channel strategy targets those CPG customers who are most likely to be involved in making a purchase transaction decision. Typically, proper market and consumer segmentation first requires the CPG firm to select the most appropriate consumer segmentation approach. There are generally four segmentation methodologies from which a CPG firm focused on a developing market can segment its intended consumers on: a) those including demographic elements, b) those including psychographic qualities c) those based on behavioral factors, and/or d) those such as geographic factors (Maina, 2015). Selecting one of these developing market segmentation solutions over another will have a profound effect on the types of consumer segments for a given CPG firm. Thus, in the case of a developing market like Jordan, its relatively small labor force at about 2.2 million along with its industrial production output of some $1.4 \%$ per annum implies that the multi-channel marketing strategy that a CPG retailer should adopt must be more subdued. That is, such a CPG retailer's multi-channel marketing strategy should integrate a more traditional marketing mix rather than online channels that many if not most of its consumers would not be able to access.

The correlation of distribution channels influencing market penetration suggested that on-ground channels represented the most marketing channels. These being the channels that firms in developing markets used for market penetration seen in the $75.6 \%$ data outcome. The on-ground channels benefit from factors such as product convenience, sufficient inventory, consumer accessibility and the overall rapidity in market distribution .Likewise, developed markets preferred online channels for market penetration with $90.2 \%$ outcome .This result emphasizes the importance of on-ground marketing channels in which developing markets and developed markets have focused for the main marketing channels for market entry .Hence, CPG firms tend to cancel the on-ground channels especially following product acceptance. Consequently, the analysis of market entry strategies relying on multiple marketing channels should be seen as a market necessity. The result is that the firm entering both developing and developed markets is able to identify a better distribution strategyAdditionally, there is strong data that indicates that . Jordan promises to be a growth market in the mid to long-term despite its relatively weak economic position in the region. Several reports indicate that, insofar as the retail sector is concerned, growth and consumer opportunities are on the horizon. For instance, GDP has begun to creep up towards a $9 \%$ benchmark over the last quarter, there are a host of major new shopping centers and retail outlets scheduled to open up on the country over the next several years and its customs import fees have been kept below $20 \%$ with an $8 \%$ sales tax on all products and services (????). Essentially, Jordan is well-positioned to support the introduction of a range of new CPGs from international and regional retailers. These new entrants can capitalize on Jordan's continuing reliance on traditional media channels as .a way to gain marketshare following market entry

In order to support this type of multi-channel marketing strategy relying on more on-ground marketing channels, a CPG retailer can benefit from the continuing dependence on newsprint, television and magazines as a .primary way to communicate with various segmentsOne specific multi-channel segmenting strategy that CPG marketers rely on is a psychographic oriented solution. Psychographics for a unified approach to marketing strategy development that seeks to produce a psychological map of all of a CPG's targeted consumer groups. It is this process of producing a psychological map of the target consumer groups that allows CPG marketers entering a new market to isolate specific traits, value systems and consumer lifestyles which can then be utilized to select the most appropriate marketing channels. This type of approach basically lumps the different CPG customers together into assorted subgroups. Then, while having in common some elements of the particular CPG consumer traits, these sub-groups can be themselves singularly targeted by differentiating elements. The outcome is a series of market subgroups that each have consumer traits that the CPG firm believes make them open to multi-channel marketing solutions.

\section{Limitations and direction for future research}

There are limitations and delimitations in every research study. In this instance, several key limitations exist with respect to the study's sample, selection process and design although these have largely been overcome through the study's methodology. One of the core limitations of this study relates to the sample size and selection relative to the CPG firms examined. The fact is that there is a certain amount of researcher bias to be overcome because the selection criteria for determining which firms actually merit inclusion is somewhat subjective in character (Archibald, 2016). Likewise, in relation to the 
size of the study's sample, there are of course geographical, access and authority related factors that must be considered. These are factors that prevented or limited the level of researcher access to firms that are or have expressed interest in entering developing markets with a new CPG or brand extension. Hence, in terms of the limitations, the following three factors merit further explanation and discussion:

The research project indicates that market entry strategies for developing markets and developed markets requires the consideration of specific factors. These are factors such as access to consumer credit, finance structures in order to fund inventory buffers and transportation services for the distribution channels. Likewise, a follow-on research project might examine both marketing and distribution channels rather than threads in the multi-channel marketing framework.

The study also revealed that the study's focus should be on the design of the multi-channel marketing strategy of firms entering developing markets. This is vital because there are some issues and impediments that CPG firms must understand and resolve before developing a full multi-channel marketing strategy.

This research project concentrates only on developing markets and developed markets, according to the more traditional market entry framework. The resulting strategies should incorporate both online social media channels along with community base on-ground channels. The outcome is that more appropriate marketing channels can be targeted by CPG firms entering developing markets.

Given this discussion of limitations then, some mention must be made of the ways in which they have been mitigated. First and foremost, these limitations have been mitigated through the study's methodology and, in part, its design. The use and application of descriptive statistics in tandem with inferential statistics allows the researcher to offset any bias in the sample selection criteria and process by utilizing the data to improve the goodness of fit and the confidence interval in the data. Finally, in relation to delimitations, this too is accomplished through the data selection criteria. It is important in providing delimiting factors to a study to first identify what type of firms are not included in the selection criteria process. Thus, the selection process clearly articulates what types of firms are excluded from consideration in the study either in relation to developing markets or developed markets.

\section{Appendices}

The data in the study was collected through the use of a targeted survey of CPG firms that are entering developing markets. The respondents were instructed to complete the following form. The instructions ask that respondents rate each individual response according to a numeric scale. This is based on a Likert scale which allows study respondents to basically rate their levels of agreement to the given statements (Joshi et al., 2015). This allows the data to carry a greater level of subjectivity without sacrificing objectivity. The Likert scale that has been developed for this survey is as follows: CPG Firm Expectation Levels:

5 indicates complete product success expectation

4 indicates majority agreement with product success expectation

3 indicates a medium level of product success expectation

2 indicates some level of product success expectation

1 indicates that there is minimal to no expectation of product success

\begin{tabular}{|c|c|c|c|c|c|}
\hline \multirow{2}{*}{ Multi-channel Marketing Channels } & \multicolumn{5}{|c|}{ CPG Firm Expectations } \\
\hline & 1 & 2 & 3 & 4 & 5 \\
\hline \multicolumn{6}{|l|}{ On-ground channels for credit application } \\
\hline \multicolumn{6}{|l|}{ 1. On-ground product distribution rapidity } \\
\hline \multicolumn{6}{|l|}{ 2.On-ground marketing channel elevating consumer convenience } \\
\hline \multicolumn{6}{|l|}{$\begin{array}{l}\text { 3. On-ground marketing channels that support stable data exchange in } \\
\text { the marketplace }\end{array}$} \\
\hline \multicolumn{6}{|l|}{ 4.Sufficient multi-channel marketing solutions } \\
\hline \multicolumn{6}{|l|}{$\begin{array}{l}5 \text {.On-ground marketing channel supporting easy of physical product } \\
\text { access }\end{array}$} \\
\hline On-ground and Online Marketing Channels CPGs & & & & & \\
\hline
\end{tabular}




\begin{tabular}{|l|l|l|l|l|l|}
\hline $\begin{array}{l}\text { 1. On-ground and online marketing channels supporting product } \\
\text { distribution }\end{array}$ & & & & \\
\hline $\begin{array}{l}\text { 2.On-ground and online marketing channels that support product } \\
\text { information access and accuracy }\end{array}$ & & & & & \\
\hline $\begin{array}{l}\text { 3. On-ground and online multi-channel marketing data that informs } \\
\text { distribution channel rules and procedures }\end{array}$ & & & & & \\
\hline $\begin{array}{l}\text { 4.On-ground and online solutions that provide CPG information for } \\
\text { consumers to make more informed decisions }\end{array}$ & & & & \\
\hline $\begin{array}{l}\text { 5. On-ground and online data sources that are used to improve market } \\
\text { performance }\end{array}$ & & & & \\
\hline Online Channels for Consumer Access & & & & \\
\hline $\begin{array}{l}\text { 1.Online multi-channel marketing that expands consumer availability } \\
\text { 2. Online multi-channel supports consumer access to product } \\
\text { information and data }\end{array}$ & & & & & \\
\hline $\begin{array}{l}\text { 3. Online CPG multi-channel marketing support consumer purchase } \\
\text { decisions }\end{array}$ & & & & & \\
\hline 4. Online provision of data, marketing rules and marketing procedures & & & & & \\
\hline $\begin{array}{l}\text { 5. Online access for consumers to financial support, credit services and } \\
\text { product research }\end{array}$ & & & & & \\
\hline
\end{tabular}

Table 6: Respondent Survey

\section{References}

Ailawadi, K. L., and Farris, P. W. (2017). Managing multi-and omni-channel distribution: metrics and research directions. Journal of retailing, 93(1), pp. 120-135.

Andaleeb, S. S. (2016). Market segmentation, targeting, and positioning. In Strategic marketing management in Asia: case studies and lessons across industries (pp. 179-207). Emerald Group Publishing Limited.

Archibald, M. M. (2016). Investigator triangulation: A collaborative strategy with potential for mixed methods research. Journal of Mixed Methods Research, 10(3), pp. 228-250.

Bahadir, S. C., Bharadwaj, S. G., and Srivastava, R. K. (2015). Marketing mix and brand sales in global markets: Examining the contingent role of country-market characteristics. Journal of International Business Studies, 46(5), pp. 596-619.

Banerjee, S., and Bhardwaj, P. (2019). Aligning marketing and sales in multi-channel marketing: Compensation design for online lead generation and offline sales conversion. Journal of Business Research, 105, pp. 293-305.

Bang, V. V., Joshi, S. L., and Singh, M. C. (2016). Marketing strategy in emerging markets: a conceptual framework. Journal of Strategic Marketing, 24(2), pp. 104-117.

Dadzie, K. Q., Amponsah, D. K., Dadzie, C. A., and Winston, E. M. (2017). How firms implement marketing strategies in emerging markets: An empirical assessment of the $4 \mathrm{~A}$ marketing mix framework. Journal of Marketing Theory and Practice, 25(3), pp. 234-256.

Fabbe, K., Hazlett, C., and Sinmazdemir, T. (2019). A persuasive peace: Syrian refugees' attitudes towards compromise and civil war termination. Journal of Peace Research, 56(1), pp. 103-117.

Goldschmidt Jr, A. (2018). A concise history of the Middle East. Routledge.

Hulland, J., Baumgartner, H., and Smith, K. M. (2018). Marketing survey research best practices: evidence and recommendations from a review of JAMS articles. Journal of the Academy of Marketing Science, 46(1), pp. 92-108. ibid

Jackson, S. L. (2015). Research methods and statistics: A critical thinking approach. Cengage Learning.

Joshi, A., Kale, S., Chandel, S., and Pal, D. K. (2015). Likert scale: Explored and explained. British Journal of Applied Science and Technology, 7(4), p. 396.

Jordan. (2019). Central Intelligence Agency: The World Factbook (online). Retrieved from: https://www.cia.gov/library/publications/the-world-factbook/geos/jo.html [Accessed 10 Apr. 2019].

Kimpel, M., and Friedrich, C. (2015). The right pricing strategy for offline retailers when expanding into the online sales channel. Journal of Business and Retail Management Research, 9(2).

Maina, S. (2015). The Impact of Market Segmentation on The Sales Volume of a Company's Product or Service. Journal Management, 7(11), pp. 132-139.

Manser, P. E., Peltier, J. W., and Barger, V. A. (2017). Omni-channel marketing, integrated marketing communications and consumer engagement: A research agenda. Journal of Research in Interactive Marketing, 11(2), pp. 185-197.

McIntyre, C., Melewar, T. C., and Dennis, C. (Eds.). (2016). Multi-channel marketing, branding, and retail design: New challenges and opportunities. Emerald Group Publishing Limited. 
Pansari, A., and Kumar, V. (2017). Customer engagement: the construct, antecedents, and consequences. Journal of the Academy of Marketing Science, 45(3), pp. 294-311.

Rauch, E., Dallasega, P., and Matt, D. T. (2016). Sustainable production in emerging markets through Distributed Manufacturing Systems (DMS). J. of Cleaner Production, 135, pp. 127-138.

Ryan, C. R. (2018). Hashemite Kingdom of Jordan. In The government and politics of the Middle East and North Africa (pp. 111-136. Routledge.

Shahid, S., and Ayaz, R. (2018). Practicing Market Orientation for Customer Engagement: The Mediating Effect of Personalization and Multi-Channel Marketing.

Tian, S. B., and Da, C. H. E. N. (2016). "Hunger Marketing" Strategy and Its Application Research - Based on Apple Products. DEStech Transactions on Economics, Business and Management, (icem).

Yu, Y., Qiu, L., Chen, H., and Yen, B. P. (2018). Interplay between Traditional Media and Social Media: Moderating Role of Product Appeal. Available at SSRN 2630910.

Zhang, R. (2019). The Influence of Advertising on the Consumers' Purchasing Decision. In 1st International Conference on Business, Economics, Management Science (BEMS 2019). Atlantis Press. 